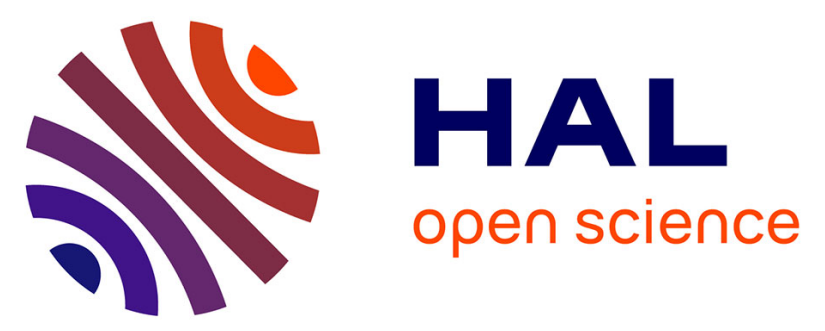

\title{
Experimental and Computational Mechanistic Studies of the $\beta$-Diketiminatoiron(II)-Catalysed Hydroamination of Primary Aminoalkenes
}

Clément Lepori, Elise Bernoud, Régis Guillot, Sven Tobisch, Jérôme Hannedouche

\section{To cite this version:}

Clément Lepori, Elise Bernoud, Régis Guillot, Sven Tobisch, Jérôme Hannedouche. Experimental and Computational Mechanistic Studies of the $\beta$-Diketiminatoiron(II)-Catalysed Hydroamination of Primary Aminoalkenes. Chemistry - A European Journal, 2018, 25 (3), pp.835-844. 10.1002/chem.201804681 . hal-02391871

\section{HAL Id: hal-02391871 \\ https://hal.science/hal-02391871}

Submitted on 30 Aug 2021

HAL is a multi-disciplinary open access archive for the deposit and dissemination of scientific research documents, whether they are published or not. The documents may come from teaching and research institutions in France or abroad, or from public or private research centers.
L'archive ouverte pluridisciplinaire HAL, est destinée au dépôt et à la diffusion de documents scientifiques de niveau recherche, publiés ou non, émanant des établissements d'enseignement et de recherche français ou étrangers, des laboratoires publics ou privés. 


\title{
Experimental and computational mechanistic studies of the $\beta$ - diketiminatoiron(II)-catalysed hydroamination of primary aminoalkenes
}

\author{
Clément Lepori, ${ }^{[a]}$ Elise Bernoud, ${ }^{[a]}$ Régis Guillot, ${ }^{[a, b]}$ Sven Tobisch ${ }^{*[c]}$ and Jérôme Hannedouche ${ }^{\star[a, b]}$
}

Dedication ((optional))

\begin{abstract}
A comprehensive mechanistic study by means of complementary experimental and computational approaches of the exo-cyclohydroamination of primary aminoalkenes mediated by the recently reported $\beta$-diketiminatoiron(II) complex $\mathbf{B}$ is presented. Kinetic analysis of the cyclisation of 2,2-diphenylpent-4-en-1-amine (1a) catalysed by $\mathbf{B}$ revealed a first-order dependence of the rate on both aminoalkene and catalyst concentrations and a primary KIE $\left(k_{H} / k_{D}\right)$ of $2.7\left(90^{\circ} \mathrm{C}\right)$. Eyring analysis afforded $\Delta H^{\ddagger}=22.2 \mathrm{kcal}^{\mathrm{mol}} \mathrm{l}^{-1}$, $\Delta S^{\ddagger}=-13.4 \mathrm{cal} \cdot \mathrm{mol}^{-1} \cdot \mathrm{K}^{-1}$. Plausible mechanistic pathways for competitive avenues of direct intramolecular hydroamination and oxidative amination have been scrutinised computationally. A kinetically challenging proton-assisted concerted $\mathrm{N}-\mathrm{C} / \mathrm{C}-\mathrm{H}$ bond forming non-insertive pathway is seen not to be accessible in the presence of a distinctly faster $\sigma$-insertive pathway. This operative pathway involves (1) rapid and reversible syn-migratory 1,2-insertion of the alkene into the $\mathrm{Fe}-\mathrm{N}_{\text {amido }} \sigma$-bond at the monomer $\left\{\mathrm{N}^{\wedge} \mathrm{N}\right\} \mathrm{Fe}$ "I amido compound; (2) turnover-limiting $\mathrm{Fe}-\mathrm{C} \sigma$-bond aminolysis at the thus generated transient $\left\{\mathrm{N}^{\wedge} \mathrm{N}\right\} \mathrm{Fe} \mathrm{e}^{\|}$alkyl intermediate and (3) regeneration of the catalytically competent $\left\{\mathrm{N}^{\wedge} \mathrm{N}\right\} \mathrm{Fe}$ " amido, which favours its dimer, likely representing the catalyst resting state, through rapid cycloamine displacement by substrate. The collectively derived mechanistic picture is consonant with all empirical data obtained from stoichiometric, catalytic and kinetics experiments.
\end{abstract}

\section{Introduction}

Over the years, the direct addition of an amine across a carboncarbon double bond, the so-called alkene hydroamination reaction has stimulated considerable interest among the scientific community as evidenced by the plethora of catalytic systems reported to promote this transformation intra- or intermolecularly. ${ }^{[1]}$ The systems reported thus far are mainly based on alkali metals, alkaline- and rare-earth elements, groups 4 and 5 elements, late transition metals or, although less common, are without any metal involved. ${ }^{[2,3,4,5]}$ Among them,

[a] C. Lepori, Dr E. Bernoud, Dr R. Guillot, Dr J. Hannedouche Institut de Chimie Moléculaire et des Matériaux d'Orsay, UMR 8182, Université Paris-Sud, Université Paris-Saclay,

rue du doyen Georges Poitou, Orsay, F-91405 (France).

E-mail: jerome.hannedouche@u-psud.fr

[b] CNRS, Orsay, F-91405 (France)

[c] Dr S. Tobisch

School of Chemistry,

University of St Andrews, Purdie Building, North Haugh, St

Andrews, KY16 9ST (United Kingdom).

E-mail: $\underline{\text { st40@st-andrews.ac.uk }}$

Supporting information for this article is given via a link at the end of the document.((Please delete this text if not appropriate)) catalysts derived from late d-block metals or free of metals offer the greatest opportunities for the development of versatile catalytic systems with a broad scope and polar functional group tolerance. Despite major advances in this direction, the development of late d-block metal hydroamination catalysts for unprotected primary aliphatic amines, arguably the most versatile amines to start an "ideal synthesis", ${ }^{6]}$ remains challenging..$^{[7,8]}$ To date, only few research groups have tackled this difficult issue with catalytic systems based on either $\mathrm{Rh}^{[2 \mathrm{j}, \mathrm{l}}$ $\mathrm{Ir},{ }^{[2, \mathrm{i}-\mathrm{k}]} \mathrm{Pt},{ }^{[2 \mathrm{t}]} \mathrm{Au},{ }^{[2 \mathrm{a}, \mathrm{b}]} \mathrm{Zn}^{[3 \mathrm{a}, \mathrm{b}]}$ or $\mathrm{Cu}^{[3 \mathrm{e}]}$ for mainly the cyclohydroamination of primary amines tethered to unactivated alkenes under mild to harsh conditions. However, these systems are restricted in scope and/or derived from noble metals of limited availability, high price and significant toxicity. Therefore, some improvements are still required to elevate late transition metal-mediated hydroamination of unprotected, primary aliphatic amines up to the requirements of a truly efficient, economical and eco-friendly methodology for the synthesis of nitrogen containing compounds. In this context and with our interest in base metal catalysis in mind ${ }^{[3+9]}$ some of us have recently reported that novel well-defined low coordinate $\beta$-diketiminatoiron(II) alkyl complex B represents the first

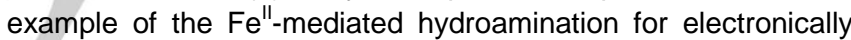
unbiased primary amines by displaying unique catalytic abilities of promoting the selective exo-cyclohydroamination of primary alkenylamines (Scheme 1). ${ }^{[3]}$

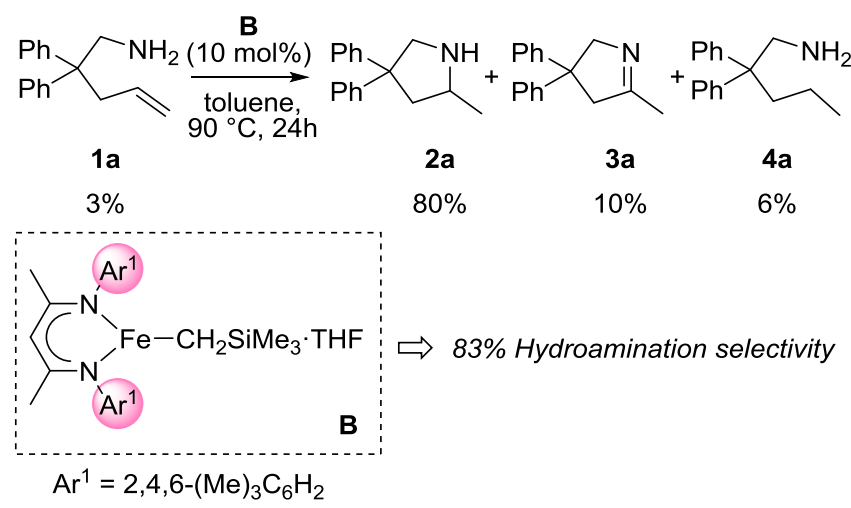

Scheme 1. Selective cyclohydroamination of 2,2-diphenylpent-4-en-1-amine (1a) catalysed by the well-defined $\beta$-diketiminato iron(II) alkyl complex $\mathbf{B}^{\left[{ }^{[3]}\right]}$

Indeed, optimisation studies have shown that complex $\mathbf{B}$ is a competent catalyst (10 mol\%) capable of converting, for example, $97 \%$ of the benchmark substrate 1 a into $80 \%$ of pyrrolidine $2 \mathrm{a}$ after $24 \mathrm{~h}$ at $90{ }^{\circ} \mathrm{C}$ together with the formation of the oxidative amination product $3 \mathbf{a}$ and the reduced substrate $4 \mathbf{a}$ 
in 10 and $6 \%$ GC yields respectively (Scheme 1). This catalyst exhibits a reaction selectivity in favour of the hydroamination product of only $83 \%$. In our preliminary study, ${ }^{[3]}$ we demonstrated that the selectivity could be enhanced up to $96 \%$ by the addition of a catalytic amount of a moderately bulky primary amine, such as cyclopentylamine. Unfortunately, the gain in selectivity comes at the expense of the catalyst performance, as a prolonged reaction time is required to achieve complete conversion. In an attempt to guide the rational design of iron catalysts exhibiting improved capabilities for selective hydroamination catalysis, we aimed at obtaining more detailed insights into mechanistic intricacies of the iron-catalysed process We opted for a collaborative approach that involves kinetic, deuterium-labelling and stoichiometric experiments complemented by a comprehensive computational analysis. Herein, we provide the complete account of our comprehensive mechanistic investigations. As it turns out the process favours a stepwise $\sigma$-insertive pathway that involves the rapid and reversible syn-migratory insertion of the pendant alkene into the iron-amido $\sigma$-bond at a low-coordinate iron(II) complex to be followed by turnover-limiting aminolysis of the resulting ironalkyl $\sigma$-bond.

\section{Results and Discussion}

\section{Kinetic studies}

We start with a full kinetic analysis for the cyclohydroamination of $\mathbf{1 a}$ by $\mathbf{B}$ that is aimed at determining the empirical rate law, kinetic isotopic effects (KIEs) and thermodynamic parameters and also at providing insights into catalyst activation.

Empirical rate law. To determine the kinetic dependence of the cyclohydroamination upon substrate concentration, the consumption of 1a over time was monitored by $\mathrm{GC}$ analysis for different initial concentrations in substrate $\left([\mathbf{1} \mathbf{a}]_{0}=0.56-1.65 \mathrm{M}\right)$ and with a constant catalyst B concentration of $0.096 \mathrm{M}$. As shown in Figure $S 4^{[10]}$, plots of $\ln \left([\mathbf{1} \mathbf{a}]_{t} /[\mathbf{1} \mathbf{a}]_{0}\right)$ versus time are linear for more than two half-lives over the initial concentration range studied and reveal a first order dependence in amine concentration. The kinetic order in catalyst concentration was subsequently determined at constant initial substrate concentration $\left([\mathbf{1} \mathbf{a}]_{0}=0.96 \mathrm{M}\right)$ by varying the catalyst concentration over a fourfold range $([B]=0.048-0.192 \mathrm{M})$. For each catalyst concentration, the pseudo first-order rate constant $k_{\mathrm{obs}}$ is extracted from the linear plot of $\ln \left([\mathbf{1} \mathbf{a}]_{\mathrm{f}} /[\mathbf{1} \mathbf{a}]_{0}\right)$ versus time over the course of more than three half-lives. The observed linear relationship between the measured first-order rate constants $k_{\mathrm{obs}}$ and $[\mathrm{B}]$ in the considered concentration range is indicative of first-order dependence of the rate upon catalyst concentration (Figure S $5^{[10]}$ ). The kinetic data are consistent with the empirical second-order rate law given in eq. 1 , which may suggest that a single adducted aminoalkene 1a may participate in the turnover-limiting event.

$-\mathrm{d}[\mathbf{1} \mathbf{a}] / \mathrm{d} t=k_{\mathrm{H}}[\mathbf{1} \mathbf{a}]^{1}[\mathrm{~B}]^{-1}\left(k_{\mathrm{H}}(363 \mathrm{~K})=4.7 \times 10^{-4} \mathrm{M}^{-1} \mathrm{~s}^{-1}\right)$
The first-order dependence on both aminoalkene and catalyst concentrations would be reconcilable with alternative mechanistic avenues for alkene hydroamination that emerged over past years including a stepwise $\sigma$-insertive pathway ${ }^{[11]}$ featuring turnover-limiting aminolysis and a concerted protonassisted, non-insertive pathway. ${ }^{[12]}$ The stepwise $\sigma$-insertive pathway involves migratory 1,2-insertion of the alkene into the metal-amido $\sigma$-bond to be followed by protonolytic cleavage of the metal-C linkage by an adducted amine substrate molecule at the resulting metal alkyl intermediate (Scheme 2). In contrast, the concerted pathway evolves through a multi-centre transition state (TS) structure for concomitant $\mathrm{C}-\mathrm{N} / \mathrm{C}-\mathrm{H}$ bond formation at a metal amido-/amino-alkene species (Scheme 2).

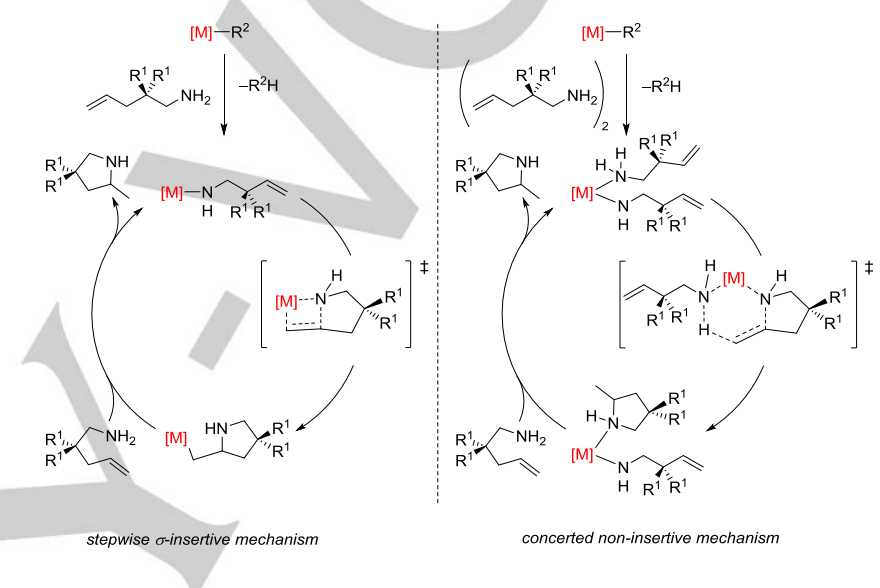

Scheme 2. Schematic representation of alternative stepwise $\sigma$-insertive and concerted proton-assisted, non-insertive mechanisms. $\mathrm{M}=$ metal

Kinetic isotope effect. The measurement of the rate of conversion of $\mathrm{N}$-deuterated $\mathbf{1 a}$ at our optimised reaction conditions gives some insight into the identity of the turnoverlimiting step. The cyclisation of $d_{2}-1 a$ in toluene at $90{ }^{\circ} \mathrm{C}$ is found much slower when compared to $\mathbf{1 a}$, which transforms into a kinetic isotope effect (KIE) $k_{H} / k_{D}$ that amounts to $2.7\left(90{ }^{\circ} \mathrm{C}\right)$ (Scheme 3). This significant primary KIE suggests that the turnover-limiting step involves $\mathrm{N}-\mathrm{H}$ (or $\mathrm{N}-\mathrm{D}$ ) bond breaking.

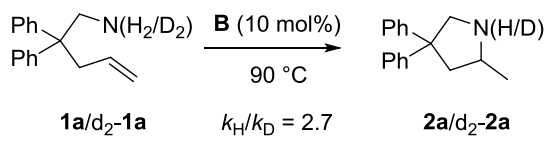

Scheme 3. H/D kinetic isotope effect for the cyclohydroamination reaction of 1a and $d_{2}-1$ a catalysed by complex $\mathbf{B}$.

Activation parameters. To further probe the nature of the turnover-limiting step, the temperature dependence of the rate for the cyclisation of $\mathbf{1 a}$ by $\mathbf{B}$ was studied. The second-order rate constant $k$ was determined at an $80-100{ }^{\circ} \mathrm{C}$ temperature range from the $k_{\text {obs }}$ values extracted from the pseudo-first order plots of $\ln [1 \mathrm{a}]$ over time. The Eyring plot of $\ln \left(k h / k_{B} \mathrm{~T}\right)$ versus $1 / \mathrm{T}$ shown in Figure 1 provides the following activation parameters: $\Delta H^{\ddagger}=$ $22.2 \mathrm{kcal} \cdot \mathrm{mol}^{-1}, \Delta S^{\ddagger}=-13.4 \mathrm{cal} \cdot \mathrm{mol}^{-1} \cdot \mathrm{K}^{-1}$. The magnitude of the 
negative $\Delta S^{\ddagger}$ value is indicative of a highly ordered TS structure associated with the turnover-limiting event.

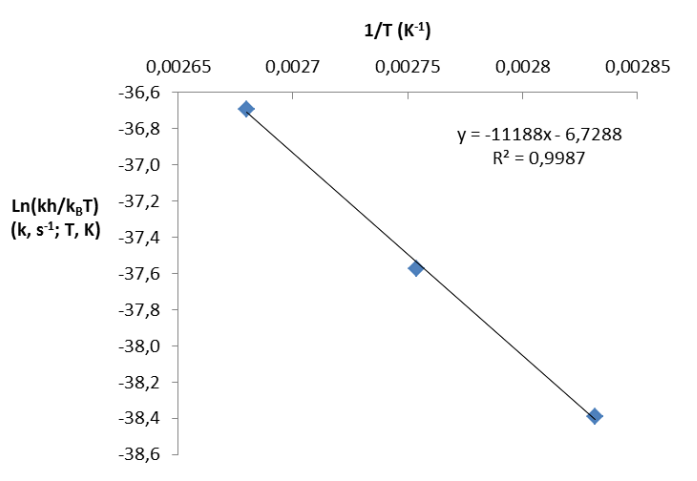

Figure 1. Eyring plot in the temperature range $80-100{ }^{\circ} \mathrm{C}$ for the cyclisation of 1a catalysed by B. $\left(\Delta H^{\ddagger}=22.2 \mathrm{kcal} \cdot \mathrm{mol}^{-1}, \Delta S^{\ddagger}=-13.4 \mathrm{cal} \cdot \mathrm{mol}^{-1} \cdot \mathrm{K}^{-1}\right)$.

Catalyst activation. To inform ourselves about the initial stages of the catalytic transformation the stoichiometric reaction of $\mathbf{B}$ with one molar equivalent of $\mathbf{1 a}$ and 2,2-dimethylpent-4-en-1amine (1b) have been conducted and monitored by ${ }^{1} \mathrm{H}$ NMR (Scheme 4). Firstly, addition of B dissolved in toluene to 1a and $\mathbf{1 b}$ at room temperature lead to the immediate formation of darkred solutions, from which red-orange crystals could be extracted. Solid-state analysis reveals the formation of centrosymmetric dimers $\left[\mathbf{D}_{1}\right]_{2}{ }^{[3]}$ and $\left[\mathbf{D}_{2}\right]_{2}$ (Figure 2$)^{[13]}$ with two iron centres featuring a distorted tetrahedral geometry that are bridged by two amido groups.

$$
\begin{array}{ll}
\mathbf{B}+\mathrm{R}^{1}=\mathrm{Ph} \\
\mathbf{1 b} \mathrm{R}^{1}=\mathrm{Me}
\end{array} \underset{\text { toluene, } \mathrm{rt}}{\left[\begin{array}{l}
\left.\mathrm{R}_{1}\right]_{2} \mathrm{R}^{1}=\mathrm{Ph}(75 \%) \\
{\left[\mathrm{D}_{2}\right]_{2} \mathrm{R}^{1}=\mathrm{Me}(73 \%)}
\end{array}\right]}
$$

Scheme 4. Stoichiometric reactivities of $\mathbf{B}$ and aminoalkenes $\mathbf{1 a}$ and $\mathbf{1 b}$. Isolated yields are in brackets and $\mathrm{Ar}^{1}=2,4,6-(\mathrm{Me})_{3} \mathrm{C}_{6} \mathrm{H}_{2}$.

Secondly, monitoring the reaction of $\mathbf{B}$ (1 equiv) with $\mathbf{1 a}(2$ equiv) by ${ }^{1} \mathrm{H}$ NMR shows the complete disappearance of the methyl signals of the $\mathrm{CH}_{2} \mathrm{SiMe}_{3}$ fragment in less than 40 (at $25^{\circ} \mathrm{C}$ ) and 10 (at $50^{\circ} \mathrm{C}$ ) minutes, respectively (Figures S1$\left.S 3^{[10]}\right)$. It clearly indicates that catalyst activation is probably not kinetically decisive at our optimised catalytic conditions $\left(90^{\circ} \mathrm{C}\right.$, $24 \mathrm{~h})$.

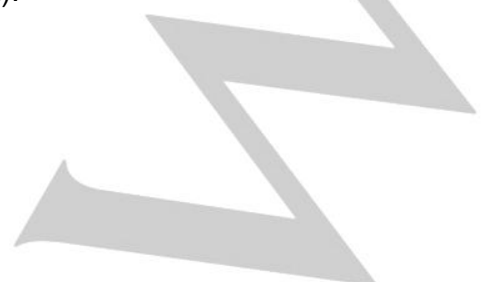

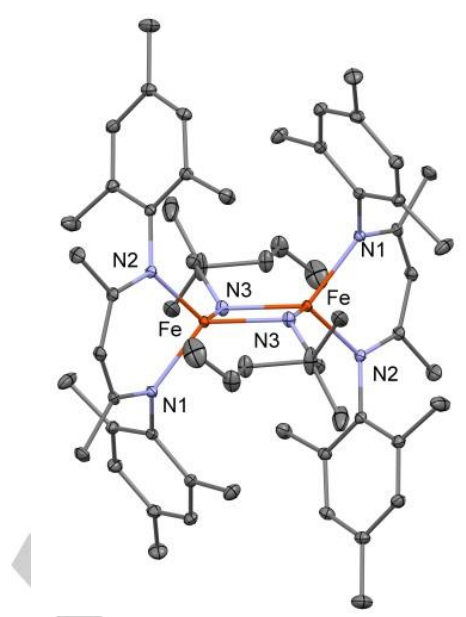

Figure 2. ORTEP diagram of $\left[\mathbf{D}_{2}\right]_{2}$ showing $30 \%$ probability ellipsoids. Hydrogen atoms are omitted for clarity.

\section{Nature of the cyclisation step}

To gain more insight into the nature of the cyclisation step, efforts have been devoted to study the reactivity of the isolated intermediate $\left[\mathbf{D}_{1}\right]_{2}$ and the stereochemistry of the $\mathrm{N}-\mathrm{H}(\mathrm{D})$ addition across the $\mathrm{C}=\mathrm{C}$ double bond.

Stoichiometric reactivity. A slurry solution of isolated iron amido dimer $\left[\mathbf{D}_{1}\right]_{2}$ was heated to $90{ }^{\circ} \mathrm{C}$ for $24 \mathrm{~h}$. After air exposure to the crude reaction mixture, GC analysis highlights the presence of $\mathbf{1 a}, \mathbf{2} \mathbf{a}, \mathbf{3 a}$ and $\mathbf{4 a}$ in a 9:16:58:18 ratio (Table 1 , entry 2). The observed formation of cycloamine $2 \mathbf{a}$ concomitantly with cyclic imine $\mathbf{3 a}$ is highly suggestive of a migratory insertion of the unsaturated alkene carbon-carbon linkage into the iron-amido bond at $\left[\mathbf{D}_{1}\right]_{2}$ or its monomer, which generates an iron alkyl intermediate. Although a high thermal stability towards $\beta$-hydride elimination has been demonstrated for some similar coordinatively unsaturated iron alkyl complexes, ${ }^{[14]}$ this intermediate is, nevertheless, expected displaying a strong tendency toward undergoing $\beta$-hydride elimination, a presumption that is reflected in the preferential formation of oxidative amination over hydroamination products. Such reactivity pattern represents a rare example of direct evidence for alkene insertion into the metal- $\mathrm{N} \sigma$-bond of structurally well-defined metal amido complexes. ${ }^{[15]}$ To our delight, the selectivity of the stoichiometric reaction can be diverted in favour of the hydroamination product by the addition of cyclopentylamine. Indeed, heating $\left[\mathbf{D}_{1}\right]_{2}$ in the presence of cyclopentylamine (1.2 equiv per $\mathrm{Fe}$ ) gives rise to $\mathbf{2 a}$ as major product (Table 1 , entry 3 ). It is worth noticing that dimer $\left[\mathbf{D}_{1}\right]_{2}$ and its alkyl precursor B display similar abilities to cyclise 1a (Table 1 , entries 4 vs. 1). It indicates that amido dimer $\left[\mathbf{D}_{1}\right]_{2}$ and its monomer are both catalytically competent to promote cyclohydroamination. Moreover, the fact that $\mathrm{C}-\mathrm{N}$ bond formation occurs commencing directly at $\left[\mathbf{D}_{1}\right]_{2}$ without requiring the assistance of an additional proton source strongly militates against a proton-assisted concerted $\mathrm{C}-\mathrm{N} / \mathrm{C}-\mathrm{H}$ bond-forming pathway. ${ }^{[11 a, 12 a]}$ 
Table 1. Influence of the catalyst structure on the reactivity and selectivity of the cyclohydroamination of $1 a^{[a]}$

\begin{tabular}{cccccc}
\hline \multirow{2}{*}{ Entry } & Catalyst & \multicolumn{5}{c}{ GC Yields [\%] } \\
\cline { 3 - 6 } & $(\mathrm{mol} \%)$ & $\mathbf{1 a}$ & $\mathbf{2 a}$ & $\mathbf{3 a}$ & $\mathbf{4 a}$ \\
\hline 1 & $\mathbf{B}(10)$ & 3 & 80 & 10 & 6 \\
$2^{[\mathrm{b}]}$ & {$\left[\mathbf{D}_{1}\right]_{2}\left(100^{[\mathrm{cc}]}\right)$} & 9 & 16 & 58 & 18 \\
$3^{[\mathrm{b}, \mathrm{d}]}$ & {$\left[\mathbf{D}_{1}\right]_{2}\left(100^{[\mathrm{cc}}\right)$} & 17 & 77 & 6 & 1 \\
$4^{[\mathrm{e}]}$ & {$\left[\mathbf{D}_{1}\right]_{2}\left(5^{[\mathrm{cc}}\right)$} & 2 & 82 & 12 & 4 \\
\hline
\end{tabular}

[a] Reaction conditions: [1a] $=0.96 \mathrm{M}$, toluene, $90^{\circ} \mathrm{C}, 24 \mathrm{~h}$ unless otherwise stated. [b] Without 1a. [c] Related to iron. [d] With cyclopentylamine $(120 \mathrm{~mol} \%$ relative to $\mathrm{Fe}$ ) as additive. [e] $21 \mathrm{~h}$

Stereochemistry of the insertion step. To ascertain the preferable pathway for $\mathrm{C}-\mathrm{N}$ bond formation its stereochemistry was established by employing complex B through isotopic labelling studies (Scheme 5). Measurements of ${ }^{3} \mathrm{~J}_{\mathrm{H}, \mathrm{H}}$ coupling constants of tosylated products evolving from cyclisation of $\mathrm{N}$ deutero-amines $(E)-\mathrm{d}_{2}-\mathbf{1 c}$ and $(Z)-\mathrm{d}_{2}-\mathbf{1 c}$ featuring a stereochemically defined carbon-carbon double bond have been performed.

$$
\text { }
$$

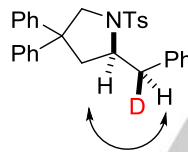$$
>95 \% \mathrm{D},{ }^{3} \mathrm{~J}_{\mathrm{H}, \mathrm{H}}=11.2 \mathrm{~Hz}
$$$$
\text { (ch) }
$$

$>95 \% \mathrm{D},{ }^{3} \mathrm{~J}_{\mathrm{H}, \mathrm{H}}=3.2 \mathrm{~Hz}$
Scheme 5. Isotopic labelling studies aimed at determining the stereochemistry of the insertion step.

The comparison with proteo amine $(E)$-1c reveals that in both cases only one diastereomer is formed with the exclusive incorporation $(>95 \%)$ of deuterium at the nitrogen's $\beta$-position and syn-addition of the $\mathrm{N}-\mathrm{D}$ bond across the $\mathrm{C}=\mathrm{C}$ bond. ${ }^{[10,16]}$ The syn-stereochemistry clearly hints towards $\mathrm{C}-\mathrm{N}$ bond formation to preferably proceeding through syn-1,2 migratory insertion.

\section{Computational study}

To further inform our mechanistic understanding, we embarked on a detailed computational perusal of plausible mechanistic pathways for rival avenues of direct intramolecular hydroamination ( $\mathrm{HA}$ ) and oxidative amination $(\mathrm{OA})$ of 2,2dimethylpent-4-en-1-amine $\mathbf{1 b}(\equiv \mathrm{S})$ by $\beta$-diketaminato $\left\{\mathrm{N}^{\wedge} \mathrm{N}\right\} \mathrm{Fe}$ alkylsilyl precatalyst $\mathbf{B}(\equiv \mathbf{C} 1 \cdot \mathrm{T})$. Productive hydroamination of the gem-dimethyl-substituted S furnishes pyrrolidine CP1, whilst cyclic imine CP2 and reduced substrate CP3 result from traversing the oxidative amination avenue. A reliable DFT methodology (dispersion-corrected hybrid meta-GGA PW6B95D3 functional in conjunction with flexible basis sets of def2-TZVP quality and a sound treatment of bulk solvent effects ${ }^{[10]}$ has been employed.

The various plausible pathways for direct $\mathrm{HA}$ and $\mathrm{OA}$ have been examined for species adopting reasonable spin states; in all, but two steps (viz. $\beta$-hydride elimination ( $\beta \mathrm{HE}$ ) and its microscopic reverse) the quintet state is found to prevail energetically. While the presentation herein will be focusing on the most accessible pathways, a complete account of all scrutinised species can be found in the Supporting Information. In what follows, different isomers of a given species are labelled by subscript numbers.

Mechanistic avenue for direct hydroamination. Given that $\left\{\mathrm{N}^{\wedge} \mathrm{N}\right\} \mathrm{Fe}$ alkylsilyl $\mathrm{C1} \cdot \mathrm{T}(\equiv \mathrm{B})$ rapidly converts into the $\left[\left\{\mathrm{N}^{\wedge} \mathrm{N}\right\} \mathrm{Fe}(\mathrm{NHR})\right]_{2}$ C2dim ( $\left.\equiv\left[\mathbf{D}_{2}\right]_{2}\right)$ almost quantitatively in the presence of amine substrate in less than $40 \mathrm{~min}$ at $50^{\circ} \mathrm{C}$, whilst $\mathrm{HA}$ catalysis requires $24 \mathrm{~h}$ at an elevated temperature of $90^{\circ} \mathrm{C}$ to be completed (see above), one can safely conclude that the initial generation of the catalytically active $\left[\left\{\mathrm{N}^{\wedge} \mathrm{N}\right\} \mathrm{Fe}(\mathrm{NHR})\right]_{\mathrm{n}}$ compound is distinctly more facile than effective $\mathrm{HA}$ catalysis and thus not likely limiting either the catalyst turnover or the $\left\{\mathrm{N}^{\wedge} \mathrm{N}\right\} \mathrm{Fe}$ amido population. Hence, our examination starts with analysing the identity of the $\left[\left\{\mathrm{N}^{\wedge} \mathrm{N}\right\} \mathrm{Fe}^{\prime \prime}(\mathrm{NHR})\right]_{\mathrm{n}}$ compound. On the one hand, dimer C2dim is well characterised (see above), whilst amine substrate $S$ can otherwise associate at iron in several ways to stabilise its monomer C2. A moderately encumbering $\beta$-diketaminato $\left\{\mathrm{N}^{\wedge} \mathrm{N}\right\} \mathrm{Fe}$ ligation favours amine association at iron, which is seen capable of accommodating up to two amine molecules (Figure $\mathrm{S}^{[10]}$ ). Among the multitude of monomer $\left\{\mathrm{N}^{\wedge} \mathrm{N}\right\} \mathrm{Fe}$ amido species, all of which are expected to participate in rapid association/dissociation equilibria, ${ }^{[17]}$ mono adduct ${ }^{5} \mathbf{C 2} \cdot \mathbf{S}$ is found most stable, with ${ }^{5} \mathbf{C} 2$ and ${ }^{5} \mathbf{C 2} \cdot(\mathrm{S})^{2}$ are placed somewhat higher in free energy by 1.3 and $5.4 \mathrm{kcal} \mathrm{mol}^{-1}$, respectively. Hence, the various species can be expected to be populated in various, but appreciable amounts.

A dimer ${ }^{1} \mathbf{C 2 d i m}\left(\equiv\left[\mathbf{D}_{2}\right]_{2}\right.$ ) could be located that reflects the metrics of the X-ray structure of $\left[\mathbf{D}_{2}\right]_{2}$ well. It adopts a singlet as the favourable spin state and is placed $2.8 \mathrm{kcal} \mathrm{mol}^{-1}$ below ${ }^{5} \mathrm{C2} \cdot \mathrm{S}$ in free energy. Thus, the catalytically relevant $\left\{\mathrm{N}^{\wedge} \mathrm{N}\right\} \mathrm{Fe} \mathrm{e}^{\|}$ amido favours its dimer over all the substrate-free and substrateadducted monomer species. It renders ${ }^{1}$ C2dim a plausible candidate for the catalyst resting state, which we therefore chose (plus appropriate substrates) as reference for free energies reported throughout this study, unless noted otherwise. However, monomer ${ }^{5} \mathbf{C 2} \cdot(\mathrm{S})^{\mathrm{n}}$ species and not ${ }^{1} \mathbf{C 2} \mathbf{d i m}$, both of which are in mobile equilibria, ${ }^{[17]}$ are the direct precursor for cyclisation (see below) and thus likely representing the catalytically active species.

$\sigma$-Insertive mechanism. Migratory olefin 1,2-insertion into the $\mathrm{Fe}-\mathrm{N}_{\text {amido }} \sigma$-bond: Several conceivable trajectories for insertive cyclisation featuring an axial or equatorial approach of the olefin double bond to commence from C2' or its substrate adducts 
C2・ $(\mathrm{S})^{\mathrm{n}}$ have been examined. Notably, all the species participating in the various trajectories favourably adopt a quintet spin state, with the respective triplet species are found well separated above in free energy and are thus not accessible thermally. Moreover, all the trajectories traverse a four-centre TS structure along the minimum-energy pathway, describing a metal-assisted syn-migratory olefin 1,2-insertion into the $\mathrm{Fe}$ $\mathrm{N}_{\text {amido }} \sigma$-bond that occurs at distances of approximately $2.0 \AA$ for the emerging $\mathrm{N} \cdots \mathrm{C}$ bond (Figure $\mathrm{S}^{[10]}$ ). The further progress along the reaction path delivers $\left\{\mathrm{N}^{\wedge} \mathrm{N}\right\} \mathrm{Fe}$ alkyl intermediate C3. $(S)^{n}$ which has the azacycle bound to iron through its methylene tether together with a stabilising metal- $\mathrm{N}$ donor centre contact.

The energy profile in Figure 3 (Figures S10-S12 (10] $^{[10 v e a l s}$ that an axial approach of the $\mathrm{C}=\mathrm{C}$ linkage does prevail for $\mathrm{N}-\mathrm{C}$ bond generating cyclisation at the $\left\{\mathrm{N}^{\wedge} \mathrm{N}\right\} \mathrm{Fe}^{\prime \prime}(\mathrm{NHR})$ compound irrespective of whether none, one or two spectator substrate molecules participate. The substrate-free ${ }^{5} \mathbf{C 2}$ ' is found most competent at effecting insertive cyclisation, whilst enhanced spatial demands around the iron centre due to association of spectator substrate molecules render migratory olefin insertion at ${ }^{5} \mathbf{C 2} \cdot \mathrm{S}$ and even more so at ${ }^{5} \mathbf{C} 2^{\prime} \cdot(\mathrm{S})^{2}$ substantially less favourable on both kinetic and thermodynamic grounds. The non-competitive energy profile derived for ${ }^{5} \mathrm{C2} \cdot \cdot \mathrm{S} \rightarrow{ }^{5} \mathrm{C} 3 \cdot \mathrm{S}$ and ${ }^{5} \mathbf{C} 2^{\prime} \cdot(S)^{2} \rightarrow{ }^{5} \mathbf{C} \cdot(S)^{2}$ is a direct consequence of the necessity to activate the olefin unit through close contact with the iron centre to accomplish $\mathrm{N}-\mathrm{C}$ bond formation, which is made ever more difficult for increasing numbers of associated spectator substrate molecules with whom the $\mathrm{C}=\mathrm{C}$ linkage has to compete for access to the metal centre.

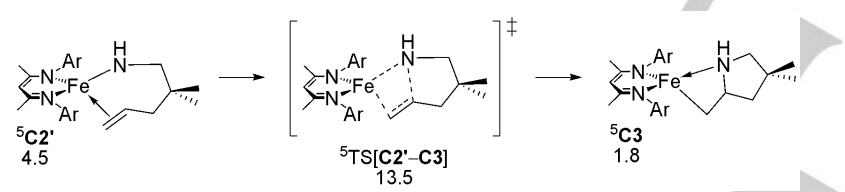

Figure 3. Most accessible pathway for migratory olefin 1,2-insertion into the $\mathrm{Fe}-\mathrm{Namido} \sigma$-bond at the catalytically relevant $\left[\left\{\mathrm{N}^{\wedge} \mathrm{N}\right\} \mathrm{Fe}(\mathrm{NHR})\right]$ complex. Free energies are given in $\mathrm{kcal} \mathrm{mol}^{-1}$ relative to $\left\{1 / 2 x^{1} \mathbf{C} 2 \mathrm{dim}+\right.$ reactants $\}$.

Migratory olefin syn-insertion into the $\mathrm{Fe}-\mathrm{N}_{\text {amido }} \sigma$-bond preferably traverses a trajectory featuring an axial olefin approach through a quasi-planar four-centre TS structure, which does not benefit from the participation of associated spectator substrate molecules. The most accessible ${ }^{5} \mathbf{C} 2{ }^{\prime} \rightleftarrows{ }^{5} \mathbf{C} 3$ pathway has a rather modest total barrier $\left(\Delta G^{\ddagger}=13.5 \mathrm{kcal} \mathrm{mol}^{-1}\right.$ relative to $\left\{1 \frac{1}{2 \times}{ }^{1} \mathbf{C 2 d i m}+\right.$ appropriate substrates $\left.\}\right)$ to traverse and is slightly exergonic. It characterises insertive ring closure to be kinetically facile and reversible.

$\mathrm{Fe}-\mathrm{C}$ azacycle tether $\sigma$-bond aminolysis: Protonolytic cleavage of the Fe-C linkage to progress from $\left\{\mathrm{N}^{\wedge} \mathrm{N}\right\} \mathrm{Fe}$ alkyl ${ }^{5} \mathrm{C} 3$ generated via the most accessible ${ }^{5} \mathbf{C 2}{ }^{\prime} \rightarrow{ }^{5} \mathbf{C} 3$ insertive cyclisation pathway requires the association of at least one molecule of $\mathrm{S}$. Various plausible trajectories for intramolecular $\mathrm{H}$ transfer have been probed (Figures S14-S16), ${ }^{[10]}$ the preferably traversed one is shown in Figure 4. After the initial facial, ${ }^{[17]}$ but somewhat uphill association of amine substrate to give adducts ${ }^{5} \mathbf{C} 3 \cdot(\mathrm{S})^{\mathrm{n}}$ aminolysis evolves through a metathesis-type TS structure that describes the cleavage of an already suitably polarised $\mathrm{N}-\mathrm{H}$ bond with simultaneous $\mathrm{C}-\mathrm{H}$ bond formation. Figure 4 reveals the cleavage of an equatorial iron alkyl $\sigma$-bond by a proton delivered from an axially iron bound, thus $\mathrm{N}-\mathrm{H}$ activated, substrate molecule to be the prevailing trajectory. The located ${ }^{5} \mathrm{TS}\left[\mathbf{C}_{1} \cdot \mathrm{S}-\mathbf{C} 4\right]$ of lowest energy represents an intermediate point on the reaction coordinate, where intramolecular $\mathrm{H}$ transfer is only partially accomplished, as evidenced by the relatively short $(1.26 \AA) \mathrm{N} \cdots \cdot \mathrm{H}$ and long $(1.54 \AA)$ $\mathrm{C} \cdots \mathrm{H}$ distances (Figure $\mathrm{S} 3^{[10]}$ ) and is directly connected to $\left\{\mathrm{N}^{\wedge} \mathrm{N}\right\} \mathrm{Fe}$ amido pyrrolidine ${ }^{5} \mathrm{C} 4$. Incoming substrate $\mathrm{S}$ readily ${ }^{[17]}$ releases pyrrolidine $\mathrm{CP} 1$ from ${ }^{5} \mathrm{C} 4$ in a virtually thermoneutral transformation $\left(\Delta G=-0.4 \mathrm{kcal} \mathrm{mol}^{-1}\right.$ for ${ }^{5} \mathrm{C} 3+\mathrm{S} \rightarrow{ }^{5} \mathrm{C} 2 \cdot \mathrm{S}+$ $\mathrm{CP} 1)$ with the regeneration of the catalytically active $\left\{\mathrm{N}^{\wedge} \mathrm{N}\right\} \mathrm{Fe}$ "I $(\mathrm{NHR})$ compound for another catalyst turnover.

The protonolytic cleavage of the $\mathrm{Fe}-\mathrm{C}$ alkyl $\sigma$-bond entails an overall barrier of $25.8 \mathrm{kcal} \mathrm{mol}^{-1}$ (relative to $\left\{1 / 2 \times{ }^{1} \mathbf{C} 2 \mathrm{dim}+\right.$ appropriate substrates\}, Figure 4) along the most accessible ${ }^{5} \mathbf{C}_{1}+\mathrm{S} \rightarrow{ }^{5} \mathbf{C} 4$ pathway. One should bear in mind that this overall barrier does not solely reflect the intrinsic ability of $S$ to effect protonolytic $\mathrm{Fe}-\mathrm{C}$ bond cleavage, since it also includes the thermodynamic penalty associated with substrate binding to C3. Furthermore, the aminolysis is downhill driven by a strong thermodynamic force $\left(\Delta G=-9.9 \mathrm{kcal} \mathrm{mol}{ }^{-1}\right.$ for $\left.{ }^{5} \mathbf{C} 3+\mathrm{S} \rightarrow{ }^{5} \mathbf{C} 4\right)$, which is primarily a consequence of the difference in strength of $\mathrm{N}-\mathrm{H}$ and $\mathrm{C}-\mathrm{H}$ bonds. All in all, the DFT-derived smooth energy profile (Figure 4) is indicative of a kinetically challenging, but nevertheless viable (in the context of the applied reaction condition) and downhill, thus irreversible, intramolecular aminolysis of the $\mathrm{Fe}-\mathrm{C}$ alkyl linkage along the energetically prevalent ${ }^{5} \mathrm{C} 3_{1}+\mathrm{S} \rightarrow{ }^{5} \mathrm{C} 4$ pathway.

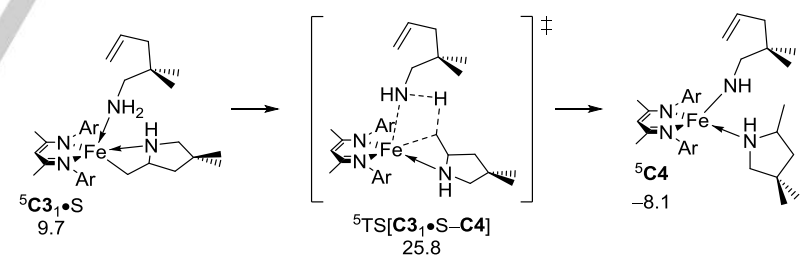

Figure 4. Most accessible pathways for $\mathrm{Fe}-\mathrm{C} \sigma$-bond aminolysis at the $\left\{\mathrm{N}^{\wedge} \mathrm{N}\right\} \mathrm{Fe}$ alkyl intermediate. Free energies are given in $\mathrm{kcal}^{-1} \mathrm{~mol}^{-1}$ relative to $\left\{1 / 2 \times{ }^{1} \mathrm{C} 2 \mathrm{dim}+\right.$ reactants $\}$.

Concerted proton-triggered cyclisation mechanism. The alternative cyclisation scenario outlined above, whereby the pyrrolidine product would be formed in a concerted single step transformation through $\mathrm{N}-\mathrm{C}$ ring closure triggered by concurrently occurring proton transfer onto the adjacent $\mathrm{C}=\mathrm{C}$ linkage, will be studied next. Similar to the findings for insertive cyclisation and protonolysis steps the quintet is the only thermally accessible spin state. The located most accessible pathway for concerted amidoalkene $\rightarrow$ cycloamine conversion is shown in Figure 5. It traverses a six-centre TS structure describing $\mathrm{N}-\mathrm{C}$ bond formation through an axial olefin approach at the $\mathrm{Fe}-\mathrm{N}_{\text {amido }} \sigma$-bond, provoked by a proton delivered from an 
equatorially bound $\mathrm{NH}$-acidified substrate molecule onto the adjacent olefin- $\mathrm{C}^{5}$ centre. When following the dominant ${ }^{5} \mathbf{C} 2 \cdot \mathrm{S} \rightarrow$ ${ }^{5} \mathbf{C} 4$ pathway the ${ }^{5} \mathrm{TS}[\mathbf{C 2} \cdot \mathrm{S}-\mathrm{C} 4]$ arrives at a $\mathrm{N} \cdots \mathrm{C}^{4}$ distance of 1.93 and features vanishing $\mathrm{N} \cdots \mathrm{H}(1.24 \AA)$ and emerging $\mathrm{C} \cdots \mathrm{H}$ $(1.47 \AA)$ bonds, all of which points to a concerted, but asynchronous proton transfer (Figure $S 17^{[10]}$ ). The large separation of the $C^{4}$ centre from the iron centre $(>3.5 \AA)$ is particularly striking and clarifies that ring closure takes places outside of the immediate vicinity of the metal centre. In sharp contrast to the inevitability of a close interaction of the $\mathrm{C}=\mathrm{C}$ bond with the metal to facilitate $\mathrm{N}-\mathrm{C}$ bond formation along the insertive cyclisation pathway, such close proximity to iron is no longer required here, since amino proton delivery activates the unsaturated carbon-carbon linkage. It furthermore renders the proton-triggered concerted cyclisation less susceptible to steric demands imposed by the ligand sphere when compared with the insertive cyclisation. After passing through the TS structure the reaction coordinate leads directly to $\mathbf{C 4}$, from which pyrrolidine $\mathrm{CP} 1$ can readily be exchanged for $\mathrm{S}$ (see above).
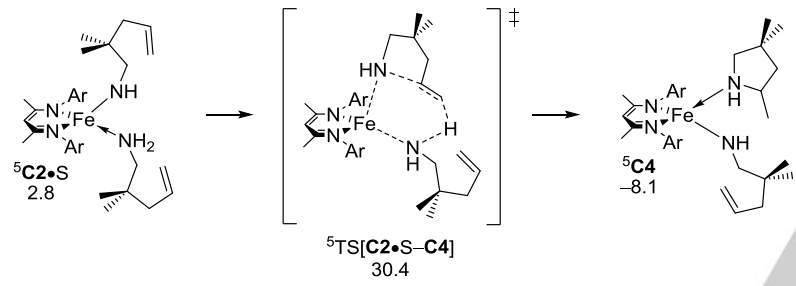

Figure 5. Most accessible pathways for $\mathrm{N}-\mathrm{C}$ ring closure with concurrent delivery of the amino proton to the olefin moiety at the catalytically relevant $\left[\left\{\mathrm{N}^{\wedge} \mathrm{N}\right\} \mathrm{Fe}(\mathrm{NHR})\right]$ compound. Free energies are given in $\mathrm{kcal}^{\mathrm{mol}}{ }^{-1}$ relative to $\left\{1 / 2 \times{ }^{1}\right.$ C2dim + reactants $\}$.

The concerted amidoalkene $\rightarrow$ cycloamine conversion along the dominant pathway for proton-assisted concurrent $\mathrm{N}-\mathrm{C} / \mathrm{C}-\mathrm{H}$ bond formation that starts from ${ }^{5} \mathbf{C 2} \cdot \mathbf{S}$ and evolves through a sixcentre TS structure has a total barrier of $30.4 \mathrm{kcal} \mathrm{mol}^{-1}$ (relative to $\left\{1 / 2 \times{ }^{1} \mathbf{C 2} \mathbf{d i m}+\right.$ appropriate substrates $\}$ ) to climb and furnishes ${ }^{5} \mathbf{C} 4$ in a process that is downhill by $10.9 \mathrm{kcal} \mathrm{mol}^{-1}$ (Figure 5). Hence, proton-assisted concerted cyclisation is irreversible as is Fe-C alkyl bond aminolysis and both steps afford compound C4. Furthermore, the process does not benefit from the association of excess substrate molecules on either thermodynamic or kinetic grounds (Figure 5), therefore paralleling the findings for insertive cyclisation and aminolysis steps.

Mechanistic avenue for oxidative amination. We shall now turn our attention to the competitive avenue for oxidative amination (OA). In accordance with a wealth of knowledge the $\left\{\mathrm{N}^{\wedge} \mathrm{N}\right\} \mathrm{Fe}$ alkyl $\mathrm{C} 3$ appears as a plausible junction from which the two separate avenues for direct intramolecular HA and OA divert. The $\beta$-hydride elimination ( $\beta \mathrm{HE}$ ) at $\mathbf{C} 3$ affords $\left\{\mathrm{N}^{\wedge} \mathrm{N}\right\} \mathrm{Fe}$ hydride C5 together with cyclic enamine $\mathrm{CP} 2$ ', which readily tautomerize into pyrroline CP2 thereafter. The regioselective migratory insertion of the aminoalkene $\mathrm{C}=\mathrm{C}$ bond into the $\mathrm{Fe}-\mathrm{H}$ linkage at substrate adducted forms of the $\left\{\mathrm{N}^{\wedge} \mathrm{N}\right\} \mathrm{Fe}$ hydride would lead to $\left\{\mathrm{N}^{\wedge} \mathrm{N}\right\} \mathrm{Fe}$ aminoalkyl $\mathbf{C 6}$, from which the reduced substrate $\mathrm{CP} 3$ is liberated through $\mathrm{Fe}-\mathrm{C}$ bond aminolysis by another molecule $S$ with the regeneration of $\left\{\mathrm{N}^{\wedge} \mathrm{N}\right\} \mathrm{Fe}(\mathrm{NHR})$ C2. Alternatively, protonolysis of substrate $\mathrm{S}$ by $\mathbf{C 5}$ would convert the $\left\{\mathrm{N}^{\wedge} \mathrm{N}\right\} \mathrm{Fe}$ hydride directly back into $\mathbf{C 2}$ with the facile liberation of $\mathrm{H}_{2}(1$ equiv).

$\beta$-Hydride elimination: For $\beta \mathrm{HE}$ to be effective a vacant coordination site cis to the alkyl and an empty metal $d$ orbital is required. However, high-spin Fe" centres have no such empty d orbital available to accept the incipient hydride's two electrons, but a triplet has. This makes a spin-crossover ${ }^{[18]}$ to a lower-spin state, which would deliver the requisite empty d orbital, almost inevitably to occur along the $\beta \mathrm{HE}$ path. ${ }^{[19]}$ The $\left\{\mathrm{N}^{\wedge} \mathrm{N}\right\} \mathrm{Fe}$ alkyl precursor favours the quintet ${ }^{5} \mathbf{C} 3$, which has a tetrahedral geometry (Figure S2 $1^{[10]}$ ), over the square-planar triplet ${ }^{3} \mathbf{C} 3$. Likewise, the initially formed product of $\beta \mathrm{HE}$ is a tetrahedral quintet $\left\{\mathrm{N}^{\wedge} \mathrm{N}\right\} \mathrm{Fe}$ cycloenamine hydride ${ }^{5} \mathrm{C} 5 \cdot \mathrm{CP} 2$ ' with the corresponding triplet is less preferable and is pseudo-square planar at the iron centre. Transition-state structures for $\beta \mathrm{HE}$ featuring vanishing $\mathrm{C} \cdots \mathrm{H}\left(1.75 / 1.53 \AA\right.$ for ${ }^{5} \mathrm{TS} /{ }^{3} \mathrm{TS}$, respectively) and emerging $\mathrm{Fe} \cdots \mathrm{H}\left(1.70 / 1.58 \AA\right.$ for ${ }^{5} \mathrm{TS} /{ }^{3} \mathrm{TS}$, respectively) bonds could be located for both spin states (Figure S2 $1^{[10]}$ ) displaying a reverse order in relative energy. The facile $\beta \mathrm{HE}$ requires a pseudo quasi-planar geometry around the iron centre whilst traversing ${ }^{3} \mathrm{TS}[\mathbf{C} 3-\mathbf{C 5} \cdot \mathrm{CP} 2$ '], although both reactant and product favour the quintet over the triplet spin state. Consequently, this process features two-state reactivity and evolves through two spin-crossover transitions. ${ }^{[10]}$

The most accessible pathway for $\beta \mathrm{HE}$ that starts from tetragonal ${ }^{5} \mathbf{C} 3$ evolves through ${ }^{3} \mathrm{TS}[\mathbf{C} 3-\mathbf{C 5} \cdot \mathrm{CP} 2$ '], which benefits from an available empty $d$ orbital at a pseudo squareplanar iron centre and decays thereafter into tetragonal ${ }^{5} \mathrm{C} 5 \cdot \mathrm{CP} 2$ ', has a total barrier of $26.7 \mathrm{kcal} \mathrm{mol}^{-1}$ (relative to $\left\{1 / 2 x^{1} \mathbf{C} 2 \mathrm{dim}+\right.$ appropriate substrates $\}$ ) to overcome (Figures $\left.\mathrm{S} 20, \mathrm{~S} 22^{[10]}\right)$. It hints to a kinetically demanding $\beta \mathrm{HE}$, which, considering the applied catalytic conditions of prolonged reaction time and elevated temperature, likely is still traversable. The initially generated cyclic enamine can be expected to readily convert into pyrroline $\mathrm{CP} 2,{ }^{[20]}$ thereby driving the overall ${ }^{5} \mathbf{C} 3 \rightarrow$ ${ }^{5} \mathrm{C5} \cdot \mathrm{CP} 2{ }^{\prime} \rightleftarrows{ }^{5} \mathrm{C} 5 \cdot \mathrm{CP} 2$ process $\left(\Delta G=-3.7 \mathrm{kcal} \mathrm{mol}^{-1}\right)$ further down thermodynamically. Moreover, the cycloimine is readily liberated ${ }^{[17]}$ by incoming $S$ to furnish substrate adducted $\left\{\mathrm{N}^{\wedge} \mathrm{N}\right\} \mathrm{Fe}$ hydride species ${ }^{5} \mathbf{C} 5 \cdot(\mathrm{S})^{\mathrm{n}}\left(\Delta G=-0.1 \mathrm{kcal} \mathrm{mol}^{-1}\right.$ for ${ }^{5} \mathrm{C} 3 \cdot \mathrm{CP} 2+\mathrm{S}$ $\left.\rightarrow{ }^{5} \mathbf{C} 2 \cdot \mathrm{S}+\mathrm{CP} 2\right)$.

Migratory olefin insertion into the $\mathrm{Fe}-\mathrm{H}$ linkage: With the $\left\{\mathrm{N}^{\wedge} \mathrm{N}\right\} \mathrm{Fe}$ hydride $\mathrm{C5}$ built, migratory insertion of the aminoalkene's $\mathrm{C}=\mathrm{C}$ bond into the $\mathrm{Fe}-\mathrm{H}$ linkage would lead to $\left\{\mathrm{N}^{\wedge} \mathrm{N}\right\} \mathrm{Fe}$ aminoalkyl C6. The pattern of substrate association onto $\mathbf{C 5}$ closely follows those for $\left\{\mathrm{N}^{\wedge} \mathrm{N}\right\} \mathrm{Fe}(\mathrm{NHR}) \mathbf{C 2}$, with all the several located $\mathbf{C 5} \cdot(\mathrm{S})^{\mathrm{n}}$ and $\mathbf{C 5} \cdot\left(\mathrm{S}^{\prime}\right)^{\mathrm{n}}$ adducts preferably adopting the quintet spin state.

Migratory olefin insertion to proceed via regioisomeric 1,2and 2,1 pathways furnishes $\left\{\mathrm{N}^{\wedge} \mathrm{N}\right\} \mathrm{Fe}$ aminoalkyl intermediates C6b and $\mathbf{C 6 a}$, respectively. The process shares common features with its microscopic reverse, viz. $\beta \mathrm{HE}$. Firstly, it features two-state reactivity and evolves through two spin-crossover transitions connecting the quintet reactant ${ }^{5} \mathrm{C} 5 \cdot(\mathrm{S})^{\mathrm{n}}$ and product 
${ }^{5} \mathbf{C 6} \cdot(\mathrm{S})^{\mathrm{n}}$ with the triplet ${ }^{3} \mathrm{TS}$ structure along the pathway of minimum energy. Secondly, additionally adducted spectator molecules $S$ do not serve stabilising any of the involved species.

We start with examining the first ${ }^{5} \mathbf{C} 5+\mathrm{n} \times \mathrm{S} \rightarrow{ }^{5} \mathbf{C 6} \mathbf{a} \cdot(\mathrm{S})^{\mathrm{n}-1}$ migratory 1,2-insertion. A detailed examination of various conceivable trajectories can be found in the Supporting Information (Figures S24-S27); here we wish to focus exclusively on the dominant ${ }^{5} \mathbf{C} 5+\mathrm{S} \rightarrow{ }^{5} \mathbf{C} 6$ a pathway. Starting from square planar ${ }^{5} \mathbf{C 5}_{1} \cdot \mathrm{S}^{\prime}$ spin crossover takes places to arrive at ${ }^{3} \mathrm{TS}\left[\mathbf{C}_{5} \cdot \mathrm{S}^{\prime}-\mathbf{C} 6 \mathbf{a}\right]$ with a distorted trigonal bipyramidal geometry around the iron centre. The triplet TS decays thereafter into quintet $\left\{\mathrm{N}^{\wedge} \mathrm{N}\right\} \mathrm{Fe}$ aminoalkyl ${ }^{5} \mathbf{C 6 a}$ through a second spin-crossover transition (Figure S2 $7^{[10]}$ ). The assessed total activation energy of $27.1 \mathrm{kcal} \mathrm{mol}^{-1}$ (relative to $\left\{1 / 2 \times{ }^{1} \mathbf{C} 2 \mathrm{dim}\right.$ + appropriate substrates, Figure 6\}) is of similar magnitude as the barrier for $\beta \mathrm{HE}$ (see above), but migratory 1,2-insertion is distinctly more downhill $\left(\Delta G=-17.9 \mathrm{kcal} \mathrm{mol}^{-1}\right)$, hence is irreversible.

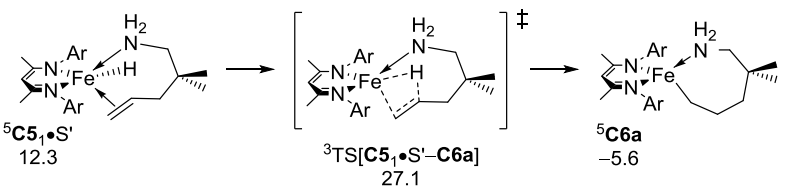

Figure 6. Most accessible pathways for migratory 1,2-insertion of the olefin double bond into the $\mathrm{Fe}-\mathrm{H}$ linkage at the $\left\{\mathrm{N}^{\wedge} \mathrm{N}\right\} \mathrm{Fe}$ hydride intermediate. Free energies are given in $\mathrm{kcal} \mathrm{mol}^{-1}$ relative to $\left\{1 / 2 \times{ }^{1} \mathbf{C} 2 \mathrm{dim}+\right.$ reactants $\}$.

The alternative migratory 2,1 -insertion via ${ }^{5} \mathbf{C} 5+S \rightarrow{ }^{5} \mathbf{C} 6 \mathbf{b}$ likewise evolves through a formal four-centre quasi-planar triplet ${ }^{3} \mathrm{TS}$ structure describing metal-mediated migratory insertion of the aminoalkene $\mathrm{C}=\mathrm{C}$ linkage into the polar $\mathrm{Fe}-\mathrm{H}$ bond, which occurs at a distances of $1.61 / 1.53 \AA$ for the emerging $\mathrm{C}^{5 \cdots} \mathrm{H}$ bond and vanishing $\mathrm{Fe} \cdot \mathrm{H}$ bonds (Figure $\mathrm{S} 28^{[10]}$ ). Among the two regioisomeric pathways migratory 1,2-insertion is predicted more rapid owing to an assessed kinetic gap of $1.5 \mathrm{kcal} \mathrm{mol}^{-1}\left(\Delta \Delta G^{\ddagger}\right)$ Figures $\left.6, \mathrm{~S}^{2} \mathrm{~g}^{[10]}\right)$ in its favour and is thus likely traversed predominantly.

Fe-C $\sigma$-bond aminolysis: The protonolytic cleavage of the Fe-C alkyl linkage at C6a by an iron-bound substrate furnishes the reduced aminoalkane $\mathrm{CP} 3$ and regenerates the catalytically active $\left\{\mathrm{N}^{\wedge} \mathrm{N}\right\} \mathrm{Fe}$ amidoalkene for another catalyst turnover. The early stage of the process sees the facile axial association ${ }^{[17]}$ of a substrate molecule, with protonolytic cleavage of the equatorial $\mathrm{Fe}-\mathrm{C}$ linkage by a proton delivered from the axially iron-bound S proceeding thereafter through ${ }^{5} \mathrm{TS}[\mathbf{C 6 a} \cdot \mathrm{S}-3 \cdot \mathrm{CP} 3$ ]. The metathesis-like TS structure describes the simultaneous cleavage/generation of $\mathrm{N}-\mathrm{H} / \mathrm{C}-\mathrm{H}$ bonds features an already weakened Fe'. $\mathrm{C}$ linkage (Figure $\mathrm{S} 31^{[10]}$ ) and is directly linked to the $\left\{\mathrm{N}^{\wedge} \mathrm{N}\right\} \mathrm{Fe}$ amido ${ }^{5} \mathrm{C2} \cdot \mathrm{CP} 3$. The newly built aminoalkane $\mathrm{CP} 3$ initially remains associated with the iron amido in ${ }^{5} \mathbf{C 2} \cdot \mathrm{CP} 3$ but could easily be replaced ${ }^{[17]}$ by aminoalkene $S(\Delta G=-0.4 \mathrm{kcal}$ $\mathrm{mol}^{-1}$ for $\left.{ }^{5} \mathbf{C 2} \cdot \mathrm{CP} 3+\mathrm{S} \rightleftarrows{ }^{5} \mathrm{C2} \cdot \mathrm{S}+\mathrm{CP} 3\right)$.

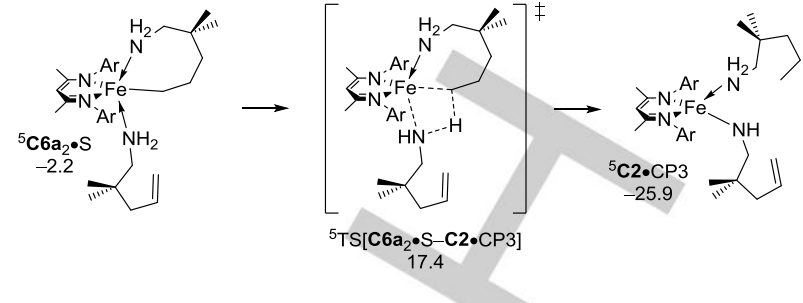

Figure 7. Most accessible pathway for $\mathrm{Fe}-\mathrm{C} \sigma$-bond aminolysis at the $\left\{\mathrm{N}^{\wedge} \mathrm{N}\right\} \mathrm{Fe}$ aminoalkyl intermediate. Free energies are given in $\mathrm{kcal} \mathrm{mol}^{-1}$ relative to $\left\{1 / 2 x^{1} \mathbf{C} 2 \mathrm{dim}+\right.$ reactants $\}$.

The protonolytic release of aminoalkane CP3 at $\mathbf{C 6 a}$ by aminoalkene $S$ is distinctly downhill, mainly driven by the enhanced strength of the $\mathrm{Fe}-\mathrm{N}_{\text {amido }} v s$. $\mathrm{Fe}-\mathrm{C}_{\text {alkyl }}$ bonds and has an affordable total barrier $\left(\Delta G^{\ddagger}=17.4 \mathrm{kcal} \mathrm{mol}^{-1}\right.$ relative to $\left\{1 / 2 \times{ }^{1} \mathbf{C} 2 \mathrm{dim}+\right.$ appropriate substrates $\}$, Figure 7). Among the two consecutive ${ }^{5} \mathbf{C} 5+\mathrm{S} \rightarrow{ }^{5} \mathbf{C} \mathbf{a}$ migratory insertion and ${ }^{5} \mathbf{C} 6 \mathbf{a}+$ $\mathrm{S} \rightarrow{ }^{5} \mathrm{C} 2 \cdot \mathrm{CP} 3 \mathrm{Fe}-\mathrm{C} \sigma$-bond aminolysis steps, the first migratory insertion dictates the overall kinetic demands (Figure 6) for the irreversible generation of reduced substrate CP3 commencing from $\left\{\mathrm{N}^{\wedge} \mathrm{N}\right\} \mathrm{Fe}$ hydride $\mathbf{C 5}$.

Protonolysis of the substrate by the $\left\{N^{\wedge} N\right\} F e$ hydride: We now examine the alternative scenario for $\left\{\mathrm{N}^{\wedge} \mathrm{N}\right\} \mathrm{Fe}$ hydride $\mathrm{C5}$ to effect protonolysis of aminoalkene $\mathrm{S}$, thereby converting C5 back directly into the catalytically active $\left\{\mathrm{N}^{\wedge} \mathrm{N}\right\} \mathrm{Fe}(\mathrm{NHR}) \mathbf{C 2}$. The process starting from either mono- and bis-substrate adducts C5• $(S)^{n}$ evolves through a metathesis-type TS structure that favours the formation of the new $\mathrm{H}-\mathrm{H}$ bond taking place between an axial $\mathrm{Fe}-\mathrm{H}$ linkage and a cis $\mathrm{N}-\mathrm{H}$ acidic amino unit over alternatively available trajectories (Figures $8, \mathrm{~S}^{-1} 5^{[10]}$ ). The assessed total activation barrier $\left(\Delta G^{\ddagger}=31.1 \mathrm{kcal} \mathrm{mol}^{-1}\right.$ relative to $\left\{1 / 2 x^{1} \mathbf{C 2 d i m}+\right.$ appropriate substrates $\}$, Figure 8) appears prohibitively large and thus hints to a rather slow, if kinetically achievable at all, ${ }^{5} \mathbf{C} 5+\mathrm{S} \rightarrow{ }^{5} \mathbf{C} 2{ }^{\prime}+\mathrm{H}_{2}$ substrate protonolysis by $\left\{\mathrm{N}^{\wedge} \mathrm{N}\right\} \mathrm{Fe}$ hydride $\mathrm{C5}$. In the presence of a stepwise generation of aminoalkane CP3 from C5, which is distinctly more accessible kinetically (cf. Figures 6,7 ), one can safely conclude that $\mathbf{C 5}$ is unlikely effecting protonolysis of the substrate.

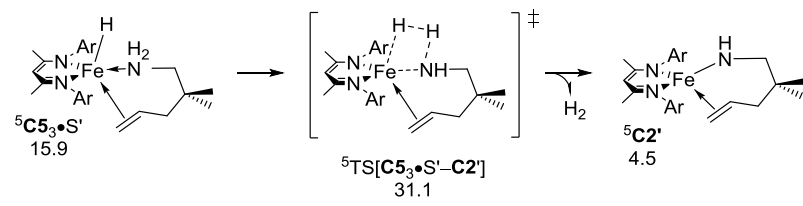

Figure 8. Most accessible pathways for protonolysis of substrate $\mathrm{S}$ by $\left\{\mathrm{N}^{\wedge} \mathrm{N}\right\} \mathrm{Fe}$ hydride $\mathrm{C} 5$ through liberation of $\mathrm{H}_{2}$. Free energies are given in kcal $\mathrm{mol}^{-1}$ relative to $\left\{1 / 2 x^{1} \mathbf{C} 2 \mathrm{dim}+\right.$ reactants $\}$.

\section{Proposed catalytic cycle}

The accumulated collective experimental and computational results lead us to define the preferably accessed pathways traversed along competing avenues of direct intramolecular hydroamination and oxidative amination. In all, but two steps (viz. $\beta \mathrm{HE}$ and its microscopic reverse) species involved preferably 
adopting the quintet spin state. Scheme 6 summarises the thus derived mechanistic picture exemplified for aminoalkene 1d (三 S) substrate and $\mathbf{B}(\equiv \mathbf{C 1} \cdot \mathbf{T})$. The initial facile conversion of starting material $\mathrm{C1} \cdot \mathrm{T}$ into the catalytically relevant $\left[\left\{\mathrm{N}^{\wedge} \mathrm{N}\right\} \mathrm{Fe} e^{\| \prime}(\mathrm{NHR})\right]_{\mathrm{n}}$ compound is unlikely limiting either the catalyst turnover or the $\left\{\mathrm{N}^{\wedge} \mathrm{N}\right\} \mathrm{Fe}^{\|}$amido population. The iron amido compound favours its dimer ${ }^{1} \mathbf{C 2} \operatorname{dim}\left(\equiv\left[\mathbf{D}_{\mathbf{2}}\right]_{2}\right)$, which likely corresponds to the catalyst resting state, but monomer species ${ }^{5} \mathbf{C} 2 \cdot(\mathrm{S})^{\mathrm{n}}$ appear as direct precursor for amidoalkene cyclisation and hence representing the catalytically active species.

Considering the avenue for direct HA first, a plausible pathway for concerted amidoalkene $\rightarrow$ cycloamine conversion through proton-assisted concurrent $\mathrm{N}-\mathrm{C} / \mathrm{C}-\mathrm{H}$ bond formation taking place outside of the immediate proximity of the iron centre via a six-centre TS structure is irreversible, but kinetically challenging. The observed substantial KIE is easily reconcilable with this concerted proton-assisted non-insertive pathway, but the stepwise $\sigma$-insertive pathway is equally consistent. This pathway entails a first kinetically facile, reversible insertive ${ }^{5} \mathbf{C 2}$ ' $\rightleftarrows{ }^{5} \mathrm{C} 3 \mathrm{~N}-\mathrm{C}$ bond-forming cyclisation through syn-migratory olefin 1,2-insertion into the $\mathrm{Fe}-\mathrm{N}_{\text {amido }} \sigma$-bond. It is followed by downhill, turnover-limiting ${ }^{5} \mathbf{C} 3+\mathrm{S} \rightarrow{ }^{5} \mathbf{C} 4$ protonolytic cleavage of the Fe-C $\sigma$-bond at the thus formed transient $\left\{\mathrm{N}^{\wedge} \mathrm{N}\right\} \mathrm{Fe}^{\|}$alkyl intermediate and the rapid displacement of the cycloamine by incoming substrate thereafter to regenerate the $\left\{\mathrm{N}^{\wedge} \mathrm{N}\right\} \mathrm{Fe}^{\|}$amido active catalyst complex. The proton-assisted concerted $\mathrm{N}-\mathrm{C} / \mathrm{C}-$ $\mathrm{H}$ bond-forming non-insertive pathway is seen to be kinetically prohibitive in the presence of a distinctly faster $\sigma$-insertive pathway. The magnitude of the DFT assessed kinetic disparity $\left(\Delta \Delta G^{\ddagger}=4.6 \mathrm{kcal} \mathrm{mol}^{-1}\right.$; Figures 4,5$)$ together with the observed simultaneous generation of pyrrolidine $\mathbf{2 a}$ and cyclic imine $3 \mathbf{a}$ upon heating $\left\{\mathrm{N}^{\wedge} \mathrm{N}\right\} \mathrm{Fe} e^{\|}$amido dimer $\left[\mathbf{D}_{1}\right]_{2}$, without additional amine present, let us confidently conclude that the $\sigma$-insertive pathway is exclusively traversed along the avenue for direct intramolecular hydroamination. The DFT assessed total barrier of $25.4 \mathrm{kcal} \mathrm{mol}^{-1}$ (relative to the ${ }^{1} \mathbf{C 2 d i m}$ catalyst resting state) for turnover-limiting $\left\{\mathrm{N}^{\wedge} \mathrm{N}\right\} \mathrm{Fe}-\mathrm{C}$ alkyl $\sigma$-bond aminolysis matches the empirically determined Eyring parameter $\left(\Delta G^{\ddagger}=27.1 \mathrm{kcal}\right.$ $\mathrm{mol}^{-1}(363 \mathrm{~K})$ for cyclisation of 1a, Figure 1$)$ gratifyingly well.

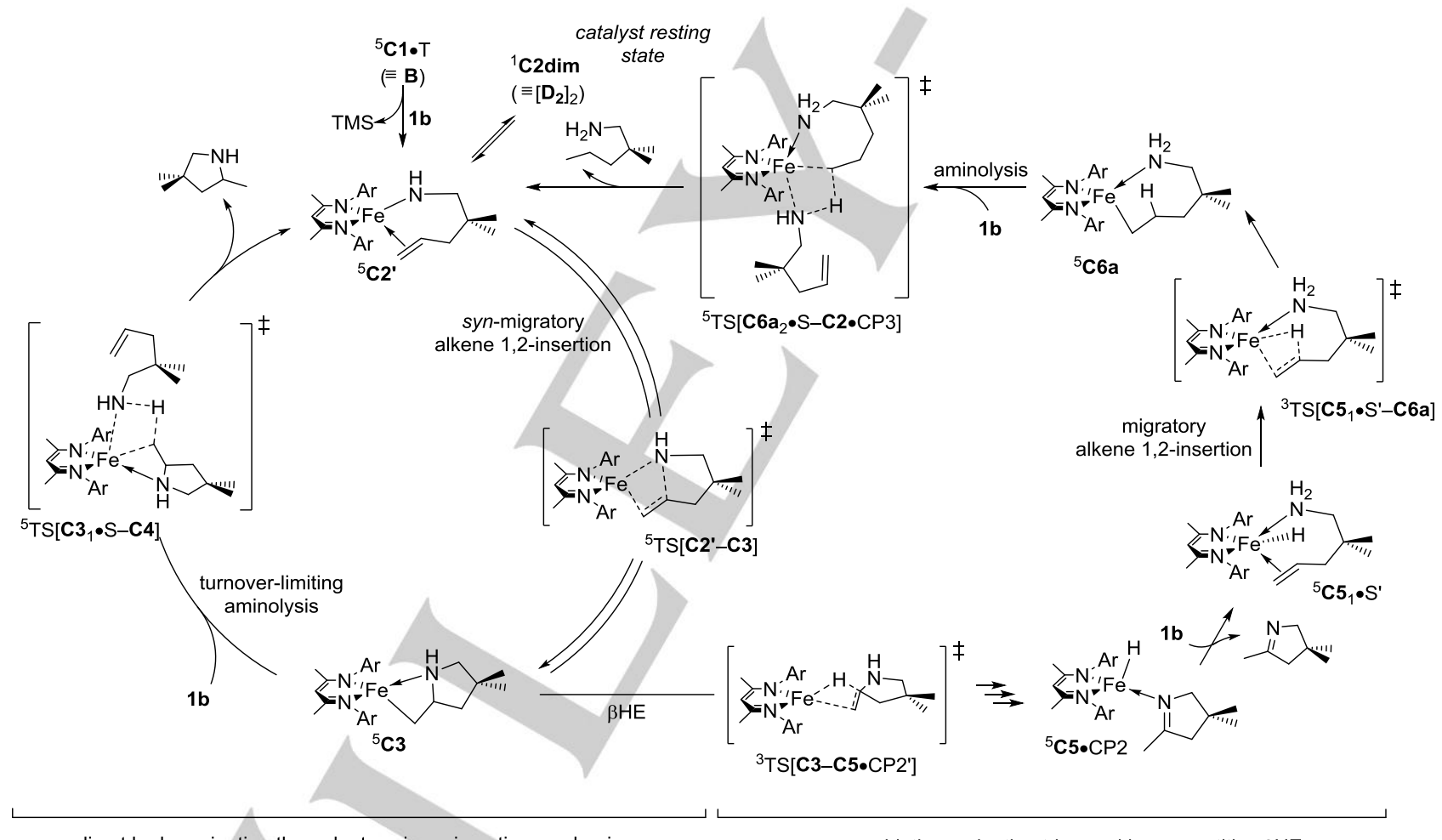

direct hydroamination through stepwise $\sigma$-insertive mechanism

oxidative amination triggered by competitive $\beta \mathrm{HE}$

Scheme 6. Proposed catalytic cycles for $\left\{\mathrm{N}^{\wedge} \mathrm{N}\right\} \mathrm{Fe}^{\|}(\mathrm{NHR})$-catalysed direct intramolecular hydroamination and rival oxidative amination

The competitive avenue for oxidative amination branches at $\left\{\mathrm{N}^{\wedge} \mathrm{N}\right\} \mathrm{Fe}^{11}$ alkyl ${ }^{5} \mathrm{C} 3$ via kinetically viable, competitive $\beta \mathrm{HE}$. Its most accessible pathway evolves through two spin-crossover transitions connecting quintet reactant and product with a triplet TS, which requires a pseudo-planar geometry at the iron centre. The reversible $\beta \mathrm{HE}$ favours the reactant and entails a total barrier of $26.7 \mathrm{kcal} \mathrm{mol}^{-1}$ (relative to the ${ }^{1} \mathbf{C 2 d i m}$ ). The thus generated short-lived hydride is seen kinetically sufficiently regioselective for migratory aminoalkene olefin 1,2-insertion to predominantly afford ${ }^{5} \mathbf{C 6 a}$. It shows two-state reactivity as its microscopic reverse does. The kinetically easy, strongly downhill $\mathrm{Fe}-\mathrm{C} \sigma$-bond protonolysis by incoming substrate releases thereafter the reduced aminoalkane, thereby closing the cycle for oxidative amination with the regeneration of the $\left\{\mathrm{N}^{\wedge} \mathrm{N}\right\} \mathrm{Fe}^{\prime \prime}$ 
amido active catalyst complex. The remarkably similar magnitude of DFT assessed total barriers for $\beta \mathrm{HE}$ and migratory olefin 1,2-insertion does not allow any firm conclusions about the nature of the turnover-limiting event along the avenue for oxidative amination. Gratifyingly, turnover-limiting ${ }^{5} \mathbf{C} 3+\mathrm{S} \rightarrow{ }^{5} \mathbf{C} 4$ aminolysis for direct hydroamination is predicted to be somewhat faster than either of these two steps. Thus, pyrrolidine can be expected as major product together with pyrroline and aminoalkane, but only should the amine concentration not drop below a level sufficient at effecting $\mathrm{Fe}-\mathrm{C} \sigma$-bond aminolysis along the avenue for direct hydroamination. The mechanistic intricacies delineated in Scheme 6 are consonant with all our empirical data obtained from both stoichiometric and catalytic studies, including the empirical second-order rate law, the substantial primary KIE and the negative activation entropy. ${ }^{[21]}$

\section{Conclusions}

Comprehensive mechanistic investigations by means of complementary experimental and computational approaches regarding the cyclohydroamination of 2,2-diphenylpent-4-en-1amine (1a) as benchmark substrate mediated by $\beta$-diketiminatoiron(II) complex $\mathbf{B}$ have been reported. Kinetic analysis revealed a first-order dependence of the rate on both aminoalkene and catalyst concentrations. These investigations lead us to define the sequence of steps preferably traversed along avenues for direct hydroamination and oxidative amination. The productive intramolecular hydroamination distinctly favours a stepwise $\sigma$-insertive mechanism over a proton-assisted concerted $\mathrm{N}-\mathrm{C} / \mathrm{C}-\mathrm{H}$ bond-forming non-insertive pathway. This entails: (1) kinetically facile, reversible ${ }^{5} \mathbf{C} 2{ }^{\prime} \rightleftarrows{ }^{5} \mathbf{C} 3$ cyclisation through syn-migratory olefin 1,2-insertion into the Fe- $\mathrm{N}_{\text {amido }} \sigma$ bond; (2) irreversible, turnover-limiting ${ }^{5} \mathrm{C} 3+\mathrm{S} \rightarrow{ }^{5} \mathrm{C} 4 \mathrm{Fe}-\mathrm{C} \sigma-$ bond aminolysis at the thus formed transient $\left\{\mathrm{N}^{\wedge} \mathrm{N}\right\} \mathrm{Fe}^{\|}$alkyl intermediate; and (3) regeneration of the catalytically active $\left\{\mathrm{N}^{\wedge} \mathrm{N}\right\} \mathrm{Fe}^{\|}$amido, which favours its dimer ${ }^{1} \mathbf{C 2 d i m}\left(\equiv[\mathrm{D} 2]_{2}\right)$, likely representing the catalyst resting state, through rapid cycloamine displacement by aminoalkene substrate. The stepwise $\sigma$ insertive pathway easily rationalises the observed substantial primary KIE and also the empirically determined negative $\Delta S^{\ddagger}$ and is supported by the direct alkene insertion into the $\mathrm{Fe}-\mathrm{N}$ amido $\sigma$-bond observed in the absence of a proton source. Its DFT predicted barrier for turnover-limiting aminolysis compares favourably with empirically determined Eyring parameter. The rival avenue for oxidative amination branches at $\left\{\mathrm{N}^{\wedge} \mathrm{N}\right\} \mathrm{Fe}{ }^{\|}$alkyl ${ }^{5} \mathrm{C} 3$ via kinetically viable, competitive $\beta \mathrm{HE}$ that evolves through two spin-crossover transitions connecting quintet reactant and product with a triplet TS. The reversible $\beta \mathrm{HE}$ releases the cyclic imine and affords short-lived $\left\{\mathrm{N}^{\wedge} \mathrm{N}\right\} \mathrm{Fe}^{\|}$hydride, which is seen kinetically sufficiently regioselective for migratory olefin 1,2insertion (also exhibiting two state reactivity) to eventually generate the reduced substrate via ensuing fast, strongly downhill $\mathrm{Fe}-\mathrm{C} \sigma$-bond protonolysis. Our combined mechanistic studies have disclosed factors governing reactivity and selectivity of alkene hydroamination of unprotected primary amines promoted by well-defined $\beta$-diketiminatoiron(II) complexes and are thus well suited assisting the design of base metal catalyst systems offering novel reactivity and selectivity for alkene hydrofunctionalisation. Efforts in this direction are currently underway.

\section{Acknowledgements ((optional))}

Financial supports from MENSR, Univ Paris Sud and the CNRS, are gratefully acknowledged.

Keywords: homogeneous catalysis $\cdot$ hydroamination $\cdot$ iron $•$ kinetics $\cdot$ density functional calculations

[1] For general and more specialised reviews on hydroamination: a) T. E Muller, K. C. Hultzsch, M. Yus, F. Foubelo, M. Tada, Chem. Rev. 2008 108, 3795-3892; b) K. D. Hesp, M. Stradiotto, ChemCatChem 2010, 2 , 1192-1207; c) J. Hannedouche, E. Schulz, Chem. Eur. J. 2013, 19 4972-4985; d) W. Li, X. Zhang, A. Reznichenko, A. Nawara-Hultzsch, K. Hultzsch, in Stereoselective Formation of Amines, Springer Berlin Heidelberg, 2014, pp. 191-260; e) E. Bernoud, C. Lepori, M. Mellah, E. Schulz, J. Hannedouche, Catal. Sci. Technol. 2015, 5, 2017-2037; f) C Lepori, J. Hannedouche, Synthesis 2017, 49, 1158-1167; g) J. G. Taylor, L. A. Adrio, K. K. Hii, Dalton Trans. 2010, 39, 1171-1175; h) V. Rodriguez-Ruiz, R. Carlino, S. Bezzenine-Lafollée, R. Gil, D. Prim, E. Schulz, J. Hannedouche, Dalton Trans. 2015, 44, 12029-12059; i) L. Huang; M. Arndt, K. Gooßen, H. Heydt, L. J. Gooßen, Chem. Rev. 2015, 115, 2596-2697.

[2] For a short selection of recent examples of alkene hydroamination promoted by second and third-row d-block elements: Rh, Ir: a) P. Gao, G. Sipos, D. Foster, R. Dorta; ACS Catal. 2017, 7, 6060-6064; b) S.C. Ensign, E. P. Vanable, G. D. Kortman, L. J. Weir, K. L. Hull, J. Am Chem. Soc. 2015, 137, 13748-13751; c) M. J. Goldfogel, C. C. Roberts, S. J. Meek, J. Am. Chem. Soc. 2014, 136, 6227-6230; d) C. S Sevov, J. (S.) Zhou, J. F. Hartwig, J. Am. Chem. Soc. 2014, 136, 32003207; e) Z. G. Specht, D. B. Grotjahn, C. E. Moore, A. L. Rheingold, Organometallics 2013, 32, 6440-6409; f) M. L. Cooke, K. Xu, B. Breit Angew. Chem., Int. Ed. 2012, 51, 10876-10879; g) S. Pan, K. Endo, T. Shibata, Org. Lett. 2012, 14, 780-783; h) C. S. Sevov, J. (S.) Zhou, J. F. Hartwig, J. Am. Chem. Soc. 2012, 134, 11960-11963; i) Y Kashiwame, S. Kuwata, T. Ikariya, Organometallics 2012, 31, 8444-8455; j) C. Hua, K. Q. Vuong, M. Bhadbhade, B. A. Messerle, Organometallics 2012, 31, 1790-1800; k) K. D. Hesp, S. Tobisch, M. Stradiotto, J. Am. Chem. Soc. 2010, 132, 413-426; I) L. D. Julian, J. F. Hartwig, J. Am. Chem. Soc. 2010, 132, 13813-13822; m) X. Shen, S. L. Buchwald, Angew. Chem. Int. Ed. 2010, 49, 564-567; n) J. R. Zhou, J. F. Hartwig, J. Am. Chem. Soc. 2008, 130, 12220-12221; o) S. Tobisch, Chem. Eur. J. 2012, 18 7248-7262. Pd, Pt: p) J. A. Gurak, Jr., K. S. Yang, Z. Liu, K. M. Engle, J. Am. Chem. Soc. 2016, 138, 5805-5808; q) D. Banerjee, K. Junge, M. Beller, Angew. Chem. Int. Ed. 2014, 53, 1630-1635; r) J. M. Pierson, E. L. Ingalls, R. D. Vo, F. E. Michael, Angew. Chem. Int. Ed. 2013, 52, 13311-13313; s) T. Xu, S. Qiu, G. Liu, J. Organomet. Chem., 2011, 693, 46-49; t) P. A. Dub, A. Bethegnies, R. Poli, Organometallics 2012 31, 294-305; u) C. B. Lavery, M. J. Ferguson, M. Stradiotto, Organometallics 2010, 29, 6125-6128; v) K. L. Toups, R. A Widenhoefer, Chem. Commun. 2010, 46, 1712-1714; w) A. M. Johns, M. Utsunomiya, C. D. Incarvito, J. F. Hartwig, J. Am. Chem. Soc. 2006, 128, 1828-1839; Ag, Au: x) K. L. Butler, M. Tragni, R. A. Widenhoefer, Angew. Chem. Int. Ed. 2012, 51, 5175-5178; y) X. Giner, C. Nájera, G. Kovács, A. Lledós, G. Ujaque, Adv. Synth. Catal. 2011, 353, 34513466; z) O. Kanno, W. Kuriyama, Z. J. Wang, F. D. Toste, Angew. Chem. Int. Ed. 2011, 50, 9919-9922; aa) Z. J. Wang, D. Benitez, E. 
Tkatchouk, W. A. Goddard III, F. D. Toste, J. Am. Chem. Soc. 2010 132, 13064-13071; ab) X. Zeng, M. M. Soleilhavoup, G. Bertrand, Org Lett. 2009, 11, 3166; ac) Z. Zhang, S. Du Lee, R. A. Widenhoefer, J. Am. Chem. Soc. 2009, 131, 5372-5373.

[3] For a short selection of recent examples of alkene hydroamination promoted by first-row d-block elements: $\mathrm{Zn}$; a) M. A. Chilleck, L. Hartenstein, T. Braun, P. W. Roesky, B. Braun, Chem. Eur. J. 2015, 21 2594-2602; b) A. Mukherjee, T. K. Sen, P. K. Ghorai, P. P. Samuel, C. Schulzke, S. K. Mandal, Chem. Eur. J. 2012, 18, 10530-10545; c) J.-W Pissarek, D. Schlesiger, P. W. Roesky, S. Blechert, Adv. Synth. Catal. 2009, 351, 2081-2085. Cu: d) R. Blieck, J. Bahri, M. Taillefer, F. Monnier, Org. Lett. 2016, 18, 1482-1485; e) H. Ohmiya, T. Moriya, M. Sawamura, Org. Lett. 2009, 11, 2145-2147. Fe: f) E. Bernoud, P. Oulié R. Guillot, M. Mellah, J. Hannedouche, Angew. Chem., Int. Ed. 2014 53, 4930-4934; g) M. S. Jung, W. S. Kim, Y. H. Shin, H. J. Jin, Y. S. Kim, E. J. Kang, Org. Lett. 2012, 14, 6262-6265; h) X. Cheng, Y. Xia, H. Xei, B. Xu, C. Zhang, Y. Li, G. Qian, X. Zhang, K. Li, W. Li, Eur. J. Org. Chem. 2008, 1929-1936; i) J. Michaux, V. Terrasson, S. Marque, J. Wehbe, D. Prim, J.-M. Campagne, Eur. J. Org. Chem. 2007, 26012603; j) C. Dal Zotto, J. Michaux, A. Zarate-Ruiz, E. Gayon, D. Virieux J.-M. Campagne, V. Terrasson, G. Pieters, A. Gaucher, D. Prim, J. Organomet. Chem. 2011, 696, 296-304; k) K. Komeyama, T. Morimoto, K. Takaki, Angew. Chem., Int. Ed. 2006, 45, 2938-2941. Ni: I) J. Pawlas, Y. Nakao, M. Kawatsura, J. F. Hartwig, J. Am. Chem. Soc 2002, 124, 3369-3679.

[4] For recent examples of formal hydroamination of alkenes promoted by first-row d-block elements: Cu: a) Y. Xi, T. W. Butcher, J. Zhang, J. F Hartwig, Angew. Chem. Int. Ed. 2016, 55, 776-780; b) D. Niu, S. L. Buchwald, J. Am. Chem. Soc. 2015, 137, 9716-9721; c) Y. Yang, S.-L. Shi, D. Niu, P. Liu, S. L. Buchwald, Science 2015, 349, 62-66; d) Y. Miki, K. Hirano, T. Satoh, M. Miura, Angew. Chem., Int. Ed. 2013, 52 10830-10834; e) S. Zhu, N. Niljianskul, S. L. Buchwald, J. Am. Chem Soc. 2013, 135, 15746-15749; f) S. Tobisch, Chem. Eur. J. 2016, 22 8290-8300. Fe: g) C. Obradors, R. M. Martinez, R. A Shenvi. J. Am. Chem. Soc. 2016, 138, 4962-4971; h) K. Zhu, M. P. Shaver, S. P. Thomas, Chem. Asian J. 2016, 11, 977-980; i) J. Gui, C.-M. Pan, Y. Jin, T. Qin, J. C. Lo, B. J. Lee, S. H. Spergel, M. E. Mertzman, W. J. Pitts, T. E. La Cruz, M. A. Schmidt, N. Darvatkar, S. Natarajan, P. S. Baran, Science 2015, 348, 886-891; j) C. B. Huehls, A. Lin, J. Yang, Org. Lett 2014, 16, 3620-3623. Co: k) H. Shigehisa, N. Koseki, N. Shimizu, M. Fujisawa, M. Niitsu, K. J. Hiroya, J. Am. Chem. Soc. 2014, 136, 13534 13537.

[5] For a short selection of representative examples of metal-freepromoted alkene hydroamination: a) A. J. Musacchio, B. C. Lainhart, X. Zhang, S. G. Naguib, T. C. Sherwood, R. R. Knowles, Science 2017, 355, 727-730; b) T. M. Nguyen, N. Manohar, D. A. Nicewicz, Angew. Chem., Int. Ed. 2014, 53, 6198-6201; c) A. R. Brown, C. Uyeda, C. A Brotherton, E. N. Jacobsen, J. Am. Chem. Soc. 2013, 135, 6747-6749; d) N. Guimond, M. J. MacDonald, V. Lemieux, A. M. Beauchemin, J. Am. Chem. Soc. 2012, 134, 16571-16577; e) N. D. Shapiro, V. Rauniyar, G. L. Hamilton, J. Wu, F. D. Toste, Nature 2011, 470, 245249; f) C.-M. Chou, J. Guin, C. Mück-Lichtenfeld, S. Grimme, A. Studer, Chem. Asian. J. 2011, 6, 1197-1209.

[6] I. S. Young, P. S. Baran, Nat. Chem. 2009, 1, 193-205.

[7] For examples of catalytic systems compatible with secondary but not primary amines: a) K. D. Hesp, M. Stradiotto, Org. Lett. 2009, 11 1449-1452; b) E. B. Bauer, G. T. S. Andavan, T. K. Hollis, R. J. Rubio, J. Cho, G. R. Kuchenbeiser, T. R. Helgert, C. S. Letko, F. S. Tham, Org Lett. 2008, 10, 1175-1178; c) reference: $2 \mathrm{~m}$.

[8] a) L. S. Hegedus, J. M. McKearin, J. Am. Chem. Soc. 1982, 104, 2444 2451; b) B. Pugin, L. M. Venanzi, J. Am. Chem. Soc. 1983, 105, 68776881.

[9] C. Lepori, P. Gómez-Orellana, A. Ouharzoune, R. Guillot, A. Lledós, G. Ujaque, J. Hannedouche, ACS Catal. 2018, 8, 4446-4451.

[10] See the Supporting Information for details.
[11] a) M. R. Gagnè, T. J. Marks, J. Am. Chem Soc. 1992, 114, 275; b) S Hong, T. J. Marks, Acc. Chem. Res. 2004, 17, 673.

[12] a) B. D. Stubbert, T. J. Marks, J. Am. Chem Soc. 2007, 129, 6149; b) L. E. N. Allen, D. J. Fox, R. J. Deeth, A. L. Gott, P. Scott, Proceedings of the $42^{\text {nd }}$ IUPAC Congress, Glasgow, UK, 2-7 August 2009.

[13] CCDC 1571112 contains the supplementary crystallographic data for this paper. These data can be obtained free of charge from the Cambridge Crystallographic Data Centre via http://www.ccdc.cam.ac.uk/Community/Requestastructure.

[14] a) J. M. Smith, R. J. Lachicotte, P. L. Holland, Organometallics 2002, 21, 4808-4814; b) N. Shirasawa, T. T. Nguyet, S. Hikichi, Y. Moro-oka, M. Akita, Organometallics 2001, 20, 3582-3598.

[15] a) P. J. Zhao, C. Krug, J. F. Hartwig, J. Am. Chem. Soc. 2005, 127 12066-12073; b) P. S. Hanley, D. Markovic, J. F. Hartwig, J. Am. Chem. Soc. 2010, 132, 6302-6303; c) P. B. White, S. S. Stahl, J. Am. Chem. Soc. 2011, 133, 18594-18597; d) P. S. Hanley, J. F. Hartwig, Angew. Chem. Int. Ed. 2013, 52, 8510-8525.

[16] T. Jiang, K. Huynh, T. Livinghouse, Synlett 2013, 24, 0193-0196.

[17] Substrate association and dissociation at the various intermediates is presumably facile and rapid equilibria are expected; examination by a linear-transit approach gave no indication that such processes are associated with a significant enthalpic barrier.

[18] a) R. Poli, Chem. Rev. 1996, 96, 2135-2204; b) J. N. Harvey, WIREs Comput. Mol. Sci. 2014, 4, 1-14.

[19] For a DFT study on $\beta$-hydride elimination in low-coordinate iron(II) and cobalt(II) alkyl complexes: S. M. Bellows, T. R. Cundari, P. L. Holland, Organometallics, 2013, 32, 4741-4751.

[20] No efforts have been made to examine the tautomerization of cyclic enamine CP2' into cycloimine CP2 - a transformation that can reasonably be expected not to invoke substantial kinetic demands.

[21] An alternative scenario for the generation of cyclic imine CP2 to involve intramolecular $\mathrm{H}$-transfer at $\mathbf{C} 3$ and subsequent $\beta \mathrm{HE}$ features an unsurmountable barrier for intramolecular $\mathrm{H}$ transfer (see Figure. $S 23^{[10]}$ ) and can thus safely be discarded in the presence of a kinetically viable $\beta \mathrm{HE}$ pathway shown in Scheme 6 . 
Entry for the Table of Contents (Please choose one layout)

Layout 1:

\section{FULL PAPER}

A comprehensive mechanistic study by means of complementary experimental and computational studies regarding the exocyclohydroamination of primary aminoalkenes mediated by a recently reported $\beta$-diketiminatoiron(II) complex is presented.

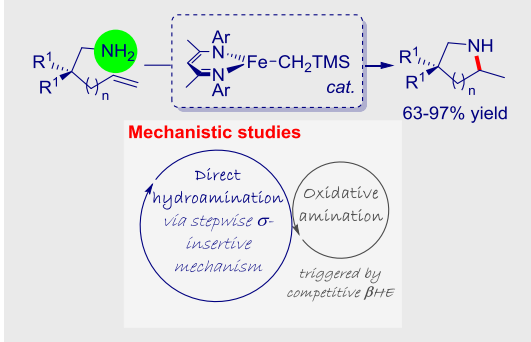

Clément Lepori, Elise Bernoud, Régis Guillot, Sven Tobisch ${ }^{\star}$ and Jérôme Hannedouche*

Page No. - Page No.

Experimental and computational mechanistic studies of the $\beta$ diketiminatoiron(II)-catalysed hydroamination of alkenes tethered to primary amines 